\title{
Considering health literacy in cardiovascular disease management: a qualitative study on healthcare professionals' and patients' perspectives
}

\section{Adèle PERRIN}

Université Claude Bernard Lyon 1

Eléonore Damiolini

Hospices Civils de Lyon

Anne-Marie Schott

Hospices Civils de Lyon

Jéremy Zermati

Université Claude Bernard Lyon 1

\section{Estelle Bravant}

Hospices Civils de Lyon

\section{François Delahaye}

Hospices Civils de Lyon

\author{
Alexandra L. Dima \\ Université Claude Bernard Lyon 1 \\ Julie HAESEBAERT ( $\nabla$ julie.haesebaert01@chu-lyon.fr ) \\ Hospices Civils de Lyon https://orcid.org/0000-0001-9109-5604
}

\section{Research Article}

Keywords: Health literacy, communication, tailored strategy, implementation, qualitative study

Posted Date: February 28th, 2022

DOI: https://doi.org/10.21203/rs.3.rs-1050514/v2

License: (c) (1) This work is licensed under a Creative Commons Attribution 4.0 International License.

Read Full License 


\section{Abstract}

Background: Implementing practices adapted to patient health literacy $(\mathrm{HL})$ is a promising avenue for improving their outcomes in the context of cardiovascular diseases (CVD). The health communication skills of healthcare professionals (HCPs) and the quality of information provided are essential for low-HL patients. We aimed to explore HCPs knowledge about HL, patients and HCPs views on current practices regarding low-HL patients, and facilitators and barriers to adapting communication to patients' HL level, in order to prepare the implementation of a complex intervention dedicated to improve CVD management for low-HL patients.

Methods: We conducted face-to-face semi-structured interviews with HCPs practicing in cardiology units and patients hospitalized for CVD. Study design and analysis were based on the Theory of Planned Behavior for HCPs and the framework of Health Literacy and Health Action for patients. Deductive and inductive thematic analysis were used. Barriers and facilitators were structured into an Ishikawa fishbone diagram and implementation strategies were selected to address resulting themes from the Expert Recommendations for Implementing Change (ERIC).

Results: Fifteen patients and 14 HCPs were interviewed. HCPs had partial knowledge of HL dimensions. Perceptions of HCPs and patients were not congruent regarding HCP-patient interactions and information provided by hospital and community HCPs. HCPs perceived they lacked validated tools and skills, and declared they adapted spontaneously their communication when interacting with low-HL patients. Patients expressed unmet needs regarding communication during hospital discharge and at return to home.

Conclusion: To implement HL-tailored practices in this setting, our results suggest that several implementation strategies will be valuable at individual (engaging patients and their family), interactional (educating and training of HCPs about $\mathrm{HL}$ ) and organizational levels (creating a multidisciplinary HCPs interest group dedicated to $\mathrm{HL}$ ).

Trial registration: The study was registered on Clinical Trials: NCT03949309.

\section{Contributions To The Literature}

1. HCPs have variable knowledge about $\mathrm{HL}$ and lack tools to adapt communication to patient $\mathrm{HL}$ level

2. HCPs and patients perceptions are not congruent regarding the communication during hospitalization but both expressed a limited continuity of care pathway

3. Some HCPs informally tailored communication when facing patients with HL difficulties

4. Differences in perceptions about HL exist among professionals, so an interprofessional approach to $\mathrm{HL}$ is essential

5. Creating an interprofessional HL-interest group, engaging patients and their families or linking patient to additional non-medical support could be effective implementation strategies to improve 


\section{Background}

Implementing practices adapted to patients health literacy $(\mathrm{HL})$ level is a major challenge to improve their outcomes in the context of cardiovascular diseases (CVD), as recently emphasized by the American Heart Association (1). HL is defined as "people's knowledge, motivation and competences to access, understand, appraise, and apply health information" (2). Understanding and implementing appropriate health behaviors regarding lifestyle and adherence to medication may be particularly difficult for low-HL CVD patients $(3,4)$ who are at high risk of medication errors following hospital discharge; $\mathrm{HL}$ acts as a mediator of other health determinants (5). Low-HL patients face greater obstacles to access healthcare, communicate with providers, and engage in their care (6). Thus, implementing practices and a culture sensitive to $\mathrm{HL}$ in health services may be beneficial to patients by improving patient self-care and health outcomes (7). Many strategies have been developed and proven effective to improve access to care by addressing $\mathrm{HL}$ issues (8), however their implementation in daily practice remains suboptimal $(1,9)$.

Healthcare professionals (HCPs) play a key role in reducing HL-related barriers to healthcare by adapting their communication to foster patient knowledge, understanding, and engagement. However, the ability of HCPs to assess patients HL level and needs is often poor $(10,11)$. HL screening is not yet implemented in daily clinical practice, partly because of the lack of awareness and training of HCPs regarding HL and because of the lack of validated tools that can be used within the time constraints of daily practice (12), and most HCPs overestimate patients' HL levels (13-17). They usually consider patients' language skills, educational level, or social status as indicators of $\mathrm{HL}$, although those do not always constitute good proxies of $\mathrm{HL}$ and can be perceived as stigmatizing (18). In addition, access to multiple and conflicting information, as well as materials that are often very difficult to understand and require simplification, contribute to the difficulties faced by low-HL patients (19). In this context, both HCPs communication skills and the quality of the written and oral information provided are essential for low-HL patients (10). Thus, raising the awareness of HCPs on HL definition, and consequences on health, and providing them with methods and tools may help them to implement HL-sensitive practices and to systematically integrate HL in CVD prevention and management (20). The 'universal precautions toolkit' has been promoted by the Agency of Health Research and Quality (AHRQ) to improve communication and $\mathrm{HL}$ implementation in CVD health care (1) and to help professionals change their practices.

The present study is part of a stepwise approach for developing and implementing a HL-tailored intervention aiming at improving HCPs skills to deliver clear and actionable information to low-HL CVD patients during the transition from hospital to home.

Getting a deeper understanding of the modifiable determinants related to HCPs communication practices and of the barriers and facilitators required for HL-tailored practices implementation is a prerequisite to identify behavior change techniques to target relevant determinants in the development of the CVD management intervention, and to select appropriate implementation strategies for this future intervention. 
The primary objective of this qualitative study was to explore HCPs knowledge about $\mathrm{HL}$, including the way they define $\mathrm{HL}$ and appraise patients $\mathrm{HL}$ level in their daily practice. As secondary objectives, we aimed to explore how HCPs tailor their communication when interacting with low-HL patients and to compare their perceptions with the needs expressed by patients. Finally, we aimed to identify modifiable determinants (barriers and facilitators) at both HCPs and patients level for implementing interventions to improve low-HL patients-HCPs interactions regarding the management of CVD.

\section{Methods}

\section{Aim, design and setting of the study}

We conducted a qualitative cross-sectional study based on face-to-face semi-structured interviews with HCPs practicing in cardiology units of the Hospices Civils de Lyon and patients hospitalized in cardiology units of the Hôpital Louis Pradel (Hospices Civils de Lyon) for either myocardial infarction (MI) or heart failure (HF). Our study and the reported results were guided by the consolidated criteria for reporting qualitative research (21).

The study was underpinned in its design and analysis by two theoretical models: the Theory of planned behavior (TBP, (22)) for HCPs and the framework of Health Literacy and Health Action (HLHA, (23)) for patients. Using the TBP constructs, we inquired about HCPs behavioral intention to adapt their communication according to patient HL level and determinants (norms, perception of control, attitude). Similarly, following the HLHA framework, we explored with patients the possible motivational and volitional determinants through which HL may affect health action dimensions such as patient-provider interaction. We inquired about their needs one month after hospital discharge.

HCPs were asked about their representation and definition of $\mathrm{HL}$, their attitudes regarding $\mathrm{HL}$, and their perceptions of control over adapting communication to patients' HL difficulties. Patients were invited to discuss their knowledge and difficulties in managing their disease, their perceived self-efficacy, their experiences after hospitalization (motivational, volitional, or system determinants), and how they accessed health information. The interview guides are presented in table A and B, Appendix 2.

To facilitate the identification of barriers and facilitators for implementing HL-tailored strategies about the management of CVD, we constructed a cause-and-effect diagram (see Discussion section) following the processes of gathering and organizing the potentials causes for an effect (24).

\section{Characteristics of participants}

We adopted a purposive maximum-variation approach to sample participants who represented different profiles of patients and HCPs.

A sample of HCPs from several professions involved in HF or AMI care was recruited: medical doctors, residents, assistant nurses, and nurses, contacted by e-mail directly or via word of mouth. An 
appointment was made with the HCPs interested in participating, during which an information letter was given to them, and oral consent was obtained before beginning the interview.

Patients were recruited within a larger mixed-methods cross-sectional study named P-ILIADE (25). All patients included in the quantitative cross-sectional survey of the P-ILIADE study during their hospitalization were invited to participate in the qualitative part of the study. We interviewed patients 30 days after hospital discharge about their experiences and how they felt about the transition and early post-hospitalization period after the acute CVD episode. We aimed to interview participants with distinct characteristics in terms of disease (HF vs AMI) and $\mathrm{HL}$ level (adequate vs low). The latter was measured using the Brief Health Literacy Screening questionnaire (BHLS, (26)) validated in French hospital settings (27) within the context of the P-ILIADE study. Information letter was given at the inclusion in P-ILIADE study, oral consent for participating in the interview was obtained before the interview.

\section{Data collection}

A PhD candidate in public health (AP), trained in interviewing and mentored by a health psychology researcher (ALD), recruited all the participants and conducted the interviews. Face-to-face interviews were carried out most of the time in a quiet hospital consultation room or, if necessary, in a waiting room. All participants were informed that the interview would be audio recorded.

We estimated that data saturation would likely be reached after approximately 15 interviews per group of participants and this was the case for patients; for HCPs, we reached saturation with 14 interviews i.e. participants expressed similar views and experiences on the topics discussed despite probing for diverse opinions. HCPs completed a brief demographic questionnaire regarding both individual (gender, age) and professional (profession, duration and place of exercise) information. Socio-demographic patient data (gender, age, disease, nationality) were retrieved from the P-ILIADE database.

\section{Data analysis}

All interviews were audio recorded and transcribed verbatim. The transcriptions were analyzed independently by two researchers (AP and ED) using the NVivo qualitative data analysis software (QSR International Pty Ltd. Version 12, 2018). Quotes were identified using gender (M (men) or W (women)), patient (PA) or HCPs (HP), and inclusion number. We conducted content analysis (28) combining deductive and inductive coding. The two theoretical models mentioned above used to develop the interview guides were also used to establish a priori the codebook for the analysis (deductive). The elimination or addition of certain themes allowed to adjust the codebook during the analysis (inductive). The two models were combined to represent the links between patient and HCPs determinants of actions and interactions with the common aim of successful transition, longer-term management, and improved health outcomes (Appendix 1). A triangulation of analyses was carried out between the AP, ED, and JH. Finally, we structured the identified barriers and facilitators using "Ishikawa" Fishbone diagram (Ishikawa, 1976 (29)). The fishbone diagram is a technique used to explore possible causes to improve quality management process and construct interventions that guide to reorganization. We have used it here to summarize factors contributing the $\mathrm{HL}$ tailored interaction and then link them to implementation 
strategies as proposed by the ERIC recommendations (30). ERIC is a compilation of implementation strategies employed to facilitate the use of evidence-based programs into healthcare contexts.

\section{Results}

\section{Sample characteristics}

We interviewed 15 patients and 14 HCPs (Table 1 and Table 2): 5 medical doctors/residents, 6 nurses, and 3 assistant nurses. Among the 14 HCPs interviewed, 9 (64\%) were women, 10 (71\%) were aged under 50 years old, and the mean (range) duration of interviews was 42 (24-57) minutes. Among the 15 patients interviewed, 10 (67\%) had HF and 5 (33\%) had an MI history, 8 (53\%) were men, 9 (60\%) had a low HL level, and their mean (range) age was 63 (39-84) years (Table 1). The mean (range) duration of interviews was 30 (18-37) minutes.

Table 1

Patients' characteristics

\begin{tabular}{|c|c|c|c|c|c|}
\hline Identifier code & Disease & Age (years) & Sex & BHLS score ( $\leq 9$ Low) & Nationality \\
\hline WPA1 & $\mathrm{HF}$ & 81 & Woman & 5 & Other than French \\
\hline MPA2 & $\mathrm{Ml}$ & 39 & Man & 9 & French \\
\hline MPA5 & $\mathrm{MI}$ & 70 & Man & 4 & French \\
\hline WPA7 & MI & 49 & Woman & 9 & French \\
\hline WPA8 & $\mathrm{HF}$ & 59 & Woman & 7 & French \\
\hline MPA9 & $\mathrm{HF}$ & 41 & Man & 4 & French \\
\hline MPA11 & $\mathrm{HF}$ & 60 & Man & 3 & Other than French \\
\hline WPA12 & $\mathrm{HF}$ & 83 & Woman & 8 & French \\
\hline WPA13 & $\mathrm{HF}$ & 45 & Woman & 8 & French \\
\hline MPA3 & $\mathrm{Ml}$ & 42 & Man & 14 & French \\
\hline MPA4 & $\mathrm{Ml}$ & 63 & Man & 15 & French \\
\hline MPA6 & $\mathrm{HF}$ & 69 & Man & 10 & French \\
\hline MPA10 & $\mathrm{HF}$ & 60 & Man & 15 & French \\
\hline WPA14 & $\mathrm{HF}$ & 80 & Woman & 12 & French \\
\hline WPA15 & HF & 84 & Woman & 12 & French \\
\hline
\end{tabular}

Abbreviations: HF: heart failure; MI: myocardial infraction; W: woman; M: man; PA; patient; BHLS, brief health literacy screening. 
Table 2

HCPs' characteristics

\begin{tabular}{|lllll|}
\hline $\begin{array}{l}\text { Identifier } \\
\text { code }\end{array}$ & Sex & $\begin{array}{l}\text { Age group (in } \\
\text { years) }\end{array}$ & Profession & $\begin{array}{l}\text { Experience in the profession (in } \\
\text { years) }\end{array}$ \\
\hline MHP1 & Man & $50-59$ & $\begin{array}{l}\text { Medical } \\
\text { doctor }\end{array}$ & 20 \\
\hline MHP2 & Man & $60-69$ & $\begin{array}{l}\text { Medical } \\
\text { doctor }\end{array}$ & 39 \\
\hline WHP3 & Woman & $50-59$ & Nurse & 23 \\
\hline WHP4 & Woman & $30-39$ & Nurse & 10 \\
\hline WHP5 & Woman & $40-49$ & Nurse & 2 \\
\hline MHP6 & Man & $30-39$ & $\begin{array}{l}\text { Medical } \\
\text { doctor }\end{array}$ & 2 \\
\hline WHP7 & Woman & $50-59$ & Nurse & 32 \\
\hline MHP8 & Man & $30-39$ & $\begin{array}{l}\text { Medical } \\
\text { doctor }\end{array}$ & 4 \\
\hline WHP9 & Woman & $30-39$ & Nurse & 10 \\
\hline WHP10 & Woman & $30-39$ & $\begin{array}{l}\text { Assistant } \\
\text { nurse }\end{array}$ & 10 \\
\hline WHP11 & Woman & $20-29$ & Resident & 4 \\
\hline WHP12 & Woman & $30-39$ & $\begin{array}{l}\text { Assistant } \\
\text { nurse }\end{array}$ & 19 \\
\hline WHP13 & Woman & $30-39$ & $\begin{array}{l}\text { Assistant } \\
\text { nurse }\end{array}$ & 20 \\
\hline MHP14 & Man & $40-49$ & $\begin{array}{l}\text { Nurse } \\
\text { Abbreviations: } \text { M: man; W: woman; HPs: healthcare professionals. }\end{array}$ \\
\hline
\end{tabular}

\section{Healthcare professionals' knowledge regarding health literacy}

Among HCPs, the level of knowledge about HL was heterogeneous, as 5/14 HCPs were not able to provide a definition of HL.Other HCPs gave partial definitions that suggested links to one or more of Nutbeam et al.'s (31) dimensions of HL (functional, interactive, and critical). Most HCPs defined HL through its interactive dimension e.g. skills that can be used to extract information and applied to different circumstances and forms of communication.

"It is the ability of a patient or a healthy person to integrate, understand, and implement actions in order to get better." WHP13 
Finally, other described HL through its critical dimension i.e. skills that allow patients to critically analyze information and use it to exert a greater control on their life.

"Literacy goes way beyond simple health literacy lyou have to know what to shop for, how to read on food elements the salt composition... you still have to know how to read, search for the information, and know what to do with it..." MHP2

The only HCPs who provided an extensive integrative definition of HL were a nurse who was trained in therapeutic patient education and studied $\mathrm{HL}$ in this context, and her colleagues with whom she had shared her knowledge about HL.

" it is the capacity of a person to first understand, to be able to read and to put into practice the things that we are going to be able to provide, the advice and recommendations related to health... and also how one can search for information, whether one is able to do so or not... " WHP3

The HCPs representations of low-HL patients were often associated with patients' social characteristics (e.g. older age, social deprivation) and current psychological state of the latter.

"It's not only about elderly patients, it's also about patients who are in great social precariousness, who do not have all the means [...] there are depressed [...]. And these patients are among the people with low literacy skills. » WHP13

Sometimes the patients' ethnic background was considered by HCPs to be a proxy of the HL level of their patients.

"There is another population there... I'm going to talk about the Mediterranean people, Spain, Italy, and Portugal, but we also have a lot of North African patients who are alone here, and these North African patients have very big problems of understanding and putting into practice...." MHP1

Limited patients' communication skills and reluctant attitudes in patient-provider interactions were also associated with low HL.

"he doesn't communicate, he doesn't answer questions, or he may be aggressive and always in denial. [...] Some people don't want to talk. A low level of literacy?"WHP13

HCPs also estimates HL level of their patients according to their behaviors or attitudes.

"when we give information, we see if it is not understood. Then, there are those who ask questions in order to avoid relapses, and those for whom treatment administration will not be optimal afterwards, they do not follow the instructions." WHP13

\section{HCP-patient interactions: current practice perceived by HCPs and patients}


HCPs reported they dealt with low-HL patients by adapting their behaviors when recognizing difficulties in patients. Most interviewed HCPs (12/14) declared that they changed their behaviors when communicating with patients for whom the difficulties are apparent.

They stated that they provided patients with simplified explanations, using layman's language and/or illustrations.

"Indeed, we're going to use simpler terms it's obvious... and then uh... we're going to ... so I'm simplifying... [...] or I'm going to explain to them what this term means, in a visual way, I try to put into images what I'm explaining. I sometimes have, we have teaching aids, we have a little plastic heart." WHP5

They also mentioned the importance of time: taking the time to let the patient ask questions and above all, taking the time to re-explain.

"Well, we take maybe more time with him [...] to explain things at greater length, maybe, repeat things to him because he hasn't understood everything." WHP10

In order to appraise the effects of their adjustment to low HL, HCPs said they observed patients' health behaviors over time. They got more confident in their effectiveness if they found that after their visit, patients took their treatment better or attended more regularly medical follow-up visits.

"I think it's really from the beginning, the first time you take the patients in charge, that you have to get into that sphere, to measure their literacy, in order to really have an impact. Afterwards, if they don't hear it from the start, they will actually come back [to the hospital]... " WHP13

In-hospital HCPs also emphasized that their goal was that patients get enough information and understanding to ensure their safety and self-care once returned home.

"what is important is that at the end of the hospital stay, the patient knows about the disease, the treatment, knows what to take, how to take it, how to adapt to the treatments" MHP1

\section{Patients' perspective}

Despite the efforts described above by hospital HCPs to adapt their communication, patients reported hospital discharge as a challenging time. Some patients (4/15) said information was missing or that explanations about treatment were not sufficient.

"I need someone to explain to me, to tell me, there you go, you've done that, the treatment corresponds to what you have, you are going to be fine. You don't just let people go out like that, without..." WPA7

They deplored having received information only from junior physicians, and 3/15 patients stated that they had not seen any senior physician to prepare their discharge. Conversely 2/15 said they received too much information or advice and they experienced it as a mental burden. 
"They put too much information in my head, you have to be rigorous, you have to take your treatment properly, you should absolutely not smoke, you shouldn't use illicit products, drugs, all that, I don't use drugs. Be careful; eat a balanced diet, not too rich."MPA9

Regarding information transmission between in-hospital and community doctors, most of the time, the information given to patients was consistent between hospital and general practitioners. However, 5/15 patients stated their general practitioner did not get information about their hospital stay from the hospital staff.

"I went to see my general practitioner yesterday, he was not aware of it, he told me, I had no feedback about what happened to you. [...] I didn't get the scanner, the hospitalization; I got nothing, no information." WPA7

In addition, relationships between patients and community HCPs did not always appear to be good and could constitute an additional barrier to the transmission of information.

"[NB The nurse] She comes once a week. She measures my blood pressure. [...] They have no clue [nurse and GP about the HF follow up process]. My GP, it's the same thing. The first time, I went to see him about it, the second time, I said, it's not even worth it. He doesn't even seem to care at all. I thought they didn't know enough about it." MPA10

Finally, some patients (4/15) expressed a need for more tailored information beyond the general information provided. For instance, they requested referral to other professionals depending on their needs, for follow-up by a psychologist, a tobacco specialist, or for obtaining daily help.

"I would have liked to see someone who's accredited, a psychologist, so that I could talk about it, about what I've been through, what I've had. Well, no, I didn't receive any guidance."WPA7

\section{Determinants for implementing HL-tailored healthcare professional-patient interactions}

\section{Barriers and facilitators perceived by HCPs}

Adapting one's behavior to patients experiencing comprehension difficulties requires adaptation and training. Even if most of the hospital HCPs interviewed were considering themselves as taking the necessary time to do so, we identified four types of barriers that may influence HL-tailored communication practices: beliefs of HCPs, the place of caregivers, inappropriate documentation, and organization (lack of time, continuity of care).

Individual HCPs belief about patients' competencies are directly associated with a feeling of low selfefficacy:

"There is also the investment of the person... The fact of thinking "well, I'll get "nothing more" [from this patient] anyway" WHP3 
We also identified challenges related to informal caregivers. Some patients' relatives took an overwhelming place in the patient-provider relationship and communication, preventing the professional from communicating directly with the patient, especially in case patients did not speak French.

"I don't like having to go through someone else, it's a third party, it's an intermediary and uh the biggest problem is that, from time to time, I know a little bit of the language, and well the interpreter will change what I said."MHP2

The available documentation that HCPs may use to support their statement or to convey information to patients did not always fit the needs of patients. It may be at the same time insufficient and too detailed.

"(we need) simple things, otherwise they don't read long blocks, some read but others tell us frankly I didn't read, or else they prefer an explanation as well." WHP4

Some HCPs pointed out (8/14) a significant lack of time or a lack of staff at the hospital to properly inform and educate patients before discharge. They also pointed out challenges in care continuity with a lack of post-hospital follow-up and a lack of communication between the medico-social and hospital domains that act like silos.

"I would need an outside network that provides us with what we don't know how to do in the hospital, which is to go into patients' homes, which is to develop relationships with nurses in private practice, which is to have a coordinator in the network, or support platforms" WHP7

These barriers were described differently depending on the profession of HCPs. Nurses put forward the lack of communication and the informal transfer of tasks from the physician to the nurse as challenging in daily practice.

"nurses often find themselves in the situation where they have to rephrase the diagnosis [...] and then the patient bursts into tears because they knew how to say the words and the patient understood, and actually for the patient, it's as if it was the first announcement, and then they're in trouble because normally it's the physician who has to make the announcement." WHP7

A similar vision was shared by the assistant nurse who pointed out a lack of physician interaction.

"Because often when we go behind them [doctors] they [Patients] say "they gave me the prescription but I didn't understand anything" (laughs). I think they don't bother the doctors because they think that the doctors don't have time but we may have more time I think. They must think like that the patients. (...) Because often behind the nurse re-explains the treatments." WHP10

However, a supportive interaction was reported between different professions i.e. between residents and assistant nurses for communication with patients.

"[NB assistant nurses], they talk to each other to see how they can make things easier. I've had quite a few assistant nurses who have helped me explain to patients what their pathology is, what treatment we're 
going to give them, and everything." WHP11

Other facilitators that HCPs reported were related to the patients' side and how they are engaged in their care.

"If the patient has, let's say, understood, and finally he/she becomes an actor ... necessarily he/she will take better care of himself/herself but ... it's like for everything else, one must understand why do things ..."MHP8

Facilitators could also relate to community care, which was considered as more individually adapted to patients' needs. For instance, interviewees declared that home care nurses and community pharmacists might take more time with the patient, in particular to explain the prescriptions.

"... the second help that we will be able to have outside the hospital it will be the pharmacist, the one who will deliver the medicines to the patients who will show him the boxes, who will show him the tablets who will tell him how he must take them...."MHP1

\section{Barriers and facilitators perceived by patients}

The main barriers to a satisfying hospital discharge for patients were the lack of follow-up and continuity of care at home. Some patients reported a need for support once they returned home (6/14), while others did not declare any specific needs or issues. However, problems related to information and communication were reported. Some patients found it difficult to ask questions to their physician because of fear of judgment, or fear of disturbing (7/14).

"Sometimes, I don't tell all my problems. I don't dare." WPA13

Patients also reported a lack of opportunity to clarify and deal with the information they received in depth.

"I had a very important question to ask them, they inserted me a stent and I wanted to know if the rest of the arteries were damaged or not. That's something I don't know anything about. So I would have liked to know if the rest of the arteries were okay. If I've got one that's got a stent and l've got one next to it that's damaged, it would be nice to know." MPA2

Patients reported the fact that nurses and assistant nurses were more present and engaged in the interaction than physicians during the hospitalization period. Patients were sometimes dissatisfied with not knowing the different roles and profession of the care team members.

"When I was there, I saw mostly residents and people, and by the way I got angry because I didn't have any communication about what was going on ... I knew what I wanted to know when I saw the physician between two doors, he talked to me in the hallway." MPA6

Thus, nurses and assistant nurses were a source of support for patients, in addition to informal caregivers (family, relatives) who were identified by patients as being their main social support. 
The available discharge programs, although very scarce, were appreciated by the few interviewed patients who were included in such programs. For instance, "PRADO" (the program developed by the French public health insurance system that allows patients to be monitored at home for 2 months after hospitalization) was reported to provide more regular follow-up and social support.

"At least I'm seeing someone, that's good. She measures my blood pressure, she weighs me..." MPA6

Contrary to the sometimes overwhelming presence of caregivers mentioned by HCPs, patients perceived them differently as very helpful. Patients used material support tools to improve their self-management capabilities, such as pillboxes to organize their treatments, and caregivers or community nurses often managed these for patients who needed it.

"They are the ones who manage the pillbox, they are the ones who manage everything" (talking about the nurses) Daughter of WPA1

\section{Summary of findings}

We grouped the identified barriers and facilitators involved in the management of CVD for low-HL patients using the "Ishikawa" Fishbone diagram (29) (figure 1) into three levels: individual level, HCPpatient interaction level, and organizational level (Appendix 3 ). Based on this structure, and guided by the $\mathrm{HL}$ universal precaution (AHRQ (32)) and the expert recommendations for implementing change (ERIC (30)), we proposed implementation strategies.

\section{Discussion}

Overall, the findings of the present study highlight the gap between the perceptions of patients and HCPs regarding the adaptation of practices to the $\mathrm{HL}$ level at each step of the patient care pathway. This qualitative study provides insight into the perspectives of patients and HCPs regarding the barriers and facilitators to implement HL-tailored communication in the management of CVD. We proposed individual, interactional and organizational strategies that may be effective in improving the uptake of evidencebased HL-tailored practices, and improving access to care and health outcomes for low-HL patients (Figure 1). These results will help in the development of the intervention planned within the broader project, aiming at reducing the gap between HL knowledge and practices as discussed below.

\section{INDIVIDUAL FACTORS}

Even though HCPs expressed their intention to tailor their communication according to patient difficulties, the complete definition of HL was not clear to them, and they expressed a lack of tools (31) to identify low-HL patients and act appropriately. Additionally, they acknowledged the need for tailored communication in the way of communicating with such patients. Hence, providing them with information to act up on their perception in order to adapt their own behavior and practices of communication would be an appropriate solution to improve patient understanding. Thus, their beliefs often call upon selfattribution regarding interaction with patients, as shown by Nache \& Trudeau et al. (33). When this 
strategy fails, they more gladly refer to external allocation, putting forward the lack of means and lack of time they face in their daily practice. We also identified that HCPs who were more in direct contact with patients (nurses, care assistants) were more likely to report delivering HL-tailored support, which is in line with the available literature advocating that addressing $\mathrm{HL}$ should be a nursing skill (34). Still, regardless of their profession, many HCPs lacked knowledge, skills, and practical tools to routinely and appropriately adopt HL-tailored practices in hospital care (35).

\section{INTERACTION FACTORS}

Interactions between patients and HCPs constitute a challenging issue to overcome. Indeed, most HCPs rely on patient commitment to express their needs, while low-HL patients can either hide their misunderstanding behind the existing communication difficulties or fear the stigma attached to them (36). HCPs mainly gave partial definition of $\mathrm{HL}$, ignoring all the dimensions of the $\mathrm{HL}$ as described by Nutbeam et al. (31) that constitute a qualitative interaction (37). The surplus of information provided at the time of hospital discharge and the need for specific information once back at home shows that HCPs may overestimate patients' understanding of the post-discharge plan (38). Upgrading methods for effective information transmission has shown to improve outcomes in terms of disease knowledge, adherence, self-efficacy, and also to reduce the hospital readmission rates for chronic disease $(3,8,39)$.

Moreover, both patients and HCPs pointed out a gap in the transition between hospital and community care. In community care, low-HL patients' difficulties to communicate with HCPs may persist with their general practitioner (GP). Communication with the GP regarding hospital stay was occasionally reported as limited. This point has to be improved since the transmission of hospital stay information cannot only rely on patients' ability to summarize their situation and represents an unnecessary responsibility for the patient. A quality improvement study has demonstrated how educational sessions can improve discharge summaries and communication with primary care (40).

\section{ORGANIZATIONAL FACTORS}

Regarding organizational challenges at the hospital, both patients and HCPs underlined staff shortages, which may limit interactions between senior physicians and patients. There also has been reported a lack of patient empathy and confidence towards residents in patient centered care and communication (41). This illustrates that a long-term patient-HCP relationship of trust needs to be built and maintained, especially in the context of chronic diseases (42). At the hospital, HCPs support each other and are complementary when dealing with patients' difficulties. This may as well allow the distribution of skills and tasks between each profile. Di Palo et al. have showed the good coordination in the management of HF patients improved health outcomes (43).

As hospital discharge is such a defining step for patient care, in addition to the strategies discussed above, further solutions need to be implemented to establish a link between hospital and community care. Once again, on a relational level, other key players such as the pairing of the nurse/care assistant or the community pharmacist may contribute to a successful discharge (44). Additionally, in terms of 
organizational resources, time needs to be allocated to this essential moment. Moreover, transition at the individual level may be improved by social support (45), for instance by mobilizing family, or proposing instrumental aids such as a pillbox.

\section{IMPLEMENTATION STRATEGIES}

Considering these results, we identified several implementation strategies that might drive the translation into practice of evidence-based HL-tailored communication strategies (39), improve patient-HCP interactions, and create a culture of $\mathrm{HL}$ in the management of CVD $(30,32)$. We summarized in Figure 2 implementation strategies that might be relevant according to our results. First, educating and training of HCPs about $H L$ is a prerequisite. Nowadays, in France, $\mathrm{HL}$ and its related issues are not part neither of the regular medical education curriculum nor of continuous education. Teaching HL within medical education should ensure all HCPs share the same core knowledge on HL, better understand the challenges related to low HL level, and develop skills to identify and communicate with low-HL patients.

Second, creating a multidisciplinary HCPs interest group dedicated to $H L$ might promote best practices for low-HL patients and induce peer-to-peer exchange at the organization level $(30,32)$. The multidisciplinary dimension of the team would enable to reflect on the role of all HCPs profiles (physicians, nurses, care assistants, students). The tasks and activities of the team may be to provide continuous training/education sessions on $\mathrm{HL}$ in the department, to develop HL toolkits specific for each profile of HCPs, and to provide evidence-based HL communicating methods. Finally, the team may act as a local champion and facilitator to develop a $\mathrm{HL}$ culture in the organization and drive changes by creating a HL improvement plan with short and long-term goals for addressing HL challenges in the context of CVD care.

Third, engaging patients and their family would also encourage HCPs to move evidence into practice $(30,32)$. This may be done by combining different approaches such as patient participation in the HL-interest group, patient involvement in designing the $H L$ plan, and setting-up a systematic patient experience feedback process (patient experience survey for instance). This could enable HCPs to identify patients' needs and priorities and confirm communication improvements and successes with low-HL patients (46).

Fourth, regarding the gap perceived by patients between hospital and ambulatory community setting, involving GPs and pharmacists alongside patients and families may help to design innovative solutions to share information, or introduce new professions such as coordinating nurse (43) or case manager for chronic disease (47). Linking patients to additional non-medical support, such as a community-based network or support by expert-patients may also help address patients' issues during care transitions.

Our study has some limitations. First, the interviewed patients were not followed directly by the HCPs interviewed, hence we cannot directly link the two perspectives. However, interviewing HCPs and their patients to compare their views would have biased discourses towards an evaluation or satisfaction interview, and induce social desirability bias. Second, for patients with communication or interactive HL 
difficulties, the expression of their issues may have been hindered by the fact that the interviews were not conducted in a neutral place but at the hospital. However, this risk was reduced by the attitude and profession of the interviewer (AP), who is not a HCP. Some HCPs may have been influenced by the educational posture of other colleagues (such as a coordinating nurse) but also provided new insights.

\section{Conclusion}

The confrontation of the perceptions of HCPs and patients regarding their interactions showed both commonalities and differences regarding the care pathway. Our study provides useful information on which implementation techniques at individual (educating and training of HCPs about HL), interactional (patient participation in the HL interest group) and organizational level (creating a multidisciplinary HCPs interest group dedicated to $\mathrm{HL}$ ). These may be effective to improve communication with low-HL CVD patients. Involving hospital and community HCPs, patients and family members within a co-construction strategy will be one of our future goals to operationalize our results in the development and implementation of the CVD management intervention.

\section{Abbreviations}

HCPs: Healthcare professionals

HL: Health Literacy

CVD: Cardiovascular Disease

Ml: Myocardial Infarction

HF: Heart Failure

TBP: Theory of Planned Behavior

HLHA: Health Literacy and Health Action

BHLS: Brief Health Literacy Screening questionnaire

GP: General Practitioner

\section{Declarations}

\section{Ethics approval and consent to participate}

Oral consent was obtained before each interview. The study received approval from the Personal Protection Committee (CPP 19034 -- ethics committee) of lle-de-France (ID-RCV: 2019-A00799-48). Consent for publication 
Not applicable.

\section{Availability of data and materials}

Not applicable.

\section{Competing interests}

The authors declare that they have no competing interest.

\section{Funding}

This study was supported by a public funding from the French ministry of health (Programme de Recherche sur la Performance du Système Hospitalier - PREPS-18-0697) for analysis and interpretation of data because it allowed the recruitment of a person for the transcription and the purchase of a $\mathrm{N}$ Vivo license.

\section{Authors' contributions}

AP conducted the interviews and was assisted by JZ for interviewing HCPs. AP and ED analyzed and interpreted the patients and HCPs data regarding the theorical model chosen. JH, AD, and AMS participated in the design of the study. FD and EB participated in the implementation of the study. All authors read and approved the final version of the manuscript.

\section{Acknowledgements}

We thank Hélène Boyer for her help in manuscript preparation.

\section{References}

1. Magnani JW, Mujahid MS, Aronow HD, Cené CW, Dickson VV, Havranek E, et al. Health Literacy and Cardiovascular Disease: Fundamental Relevance to Primary and Secondary Prevention: A Scientific Statement From the American Heart Association. Circulation [Internet]. 10 juill 2018 [cité 24 oct 2018];138. Disponible sur: https://www.ahajournals.org/doi/10.1161/CIR.0000000000000579

2. Sørensen K, Van den Broucke S, Fullam J, Doyle G, Pelikan J, Slonska Z, et al. Health literacy and public health: A systematic review and integration of definitions and models. BMC Public Health. 25 janv 2012;12:80.

3. Wali H, Hudani Z, Wali S, Mercer K, Grindrod K. A systematic review of interventions to improve medication information for low health literate populations. Res Soc Adm Pharm. 1 nov 2016;12(6):830-64.

4. Edwards M, Wood F, Davies M, Edwards A. 'Distributed health literacy': Iongitudinal qualitative analysis of the roles of health literacy mediators and social networks of people living with a longterm health condition. Health Expect Int J Public Particip Health Care Health Policy. oct 2015;18(5):1180-93. 
5. Mixon AS, Myers AP, Leak CL, Lou Jacobsen JM, Cawthon C, Goggins KM, et al. Characteristics associated with postdischarge medication errors. Mayo Clin Proc. août 2014;89(8):1042-51.

6. Pelikan JM, Ganahl K, Roethlin F. Health literacy as a determinant, mediator and/or moderator of health: empirical models using the European Health Literacy Survey dataset. Glob Health Promot. déc 2018;25(4):57-66.

7. Safeer RS, Keenan J. Health Literacy: The Gap Between Physicians and Patients. Am Fam Physician. 1 août 2005;72(3):463-8.

8. Schapira MM, Swartz S, Ganschow PS, Jacobs EA, Neuner JM, Walker CM, et al. Tailoring Educational and Behavioral Interventions to Level of Health Literacy: A Systematic Review. MDM Policy Pract [Internet]. 15 juin 2017 [cité 21 mai 2019];2(1). Disponible sur:

https://www.ncbi.nlm.nih.gov/pmc/articles/PMC6124923/

9. Sheridan SL, Halpern DJ, Viera AJ, Berkman ND, Donahue KE, Crotty K. Interventions for Individuals with Low Health Literacy: A Systematic Review. J Health Commun. 30 sept 2011;16(sup3):30-54.

10. Voigt-Barbarowicz M, Brütt AL. The Agreement between Patients' and Healthcare Professionals' Assessment of Patients' Health Literacy-A Systematic Review. Int J Environ Res Public Health. 31 mars 2020;17(7).

11. Lee TW, Lee SH, Kim HH, Kang SJ. Effective Intervention Strategies to Improve Health Outcomes for Cardiovascular Disease Patients with Low Health Literacy Skills: A Systematic Review. Asian Nurs Res. 1 déc 2012;6(4):128-36.

12. Haun JN, Valerio MA, McCormack LA, Sørensen K, Paasche-Orlow MK. Health literacy measurement: an inventory and descriptive summary of 51 instruments. J Health Commun. 2014;19 Suppl 2:302-33.

13. Lambert M, Luke J, Downey B, Crengle S, Kelaher M, Reid S, et al. Health literacy: Health professionals' understandings and their perceptions of barriers that Indigenous patients encounter. BMC Health Serv Res. 29 nov 2014;14:614.

14. Bass PFI, Wilson JF, Griffith $\mathrm{CH}$, Barnett DR. Residents' Ability to Identify Patients with Poor Literacy Skills. Acad Med. oct 2002;77(10):1039.

15. Kelly PA, Haidet P. Physician overestimation of patient literacy: A potential source of health care disparities. Patient Educ Couns. 1 avr 2007;66(1):119-22.

16. Macabasco-O'Connell A, Fry-Bowers EK. lu, à garder: Knowledge and perceptions of health literacy among nursing professionals. J Health Commun. 2011;16 Suppl 3:295-307.

17. Dickens, C. C, Lambert BL, Cromwell T, Piano MR. Nurse Overestimation of Patients' Health Literacy. J Health Commun. 4 déc 2013;18(sup1):62-9.

18. Easton $P$, Entwistle VA, Williams B. Health in the « hidden population » of people with low literacy. A systematic review of the literature. BMC Public Health. 5 août 2010;10:459.

19. Cajita MI, Rodney T, Xu J, Hladek M, Han H-R. Quality and Health Literacy Demand of Online Heart Failure Information. J Cardiovasc Nurs. 2017;32(2):156-64. 
20. Quinn F, Smith SK, Dhillon HM, Gillham C, Craig A. What do radiation therapists know about health literacy and the strategies to improve it for patients? A qualitative study. Support Care Cancer Off J Multinatl Assoc Support Care Cancer. févr 2019;27(2):649-57.

21. Tong A, Sainsbury P, Craig J. Consolidated criteria for reporting qualitative research (COREQ): a 32item checklist for interviews and focus groups. Int J Qual Health Care. 2007;19(6):349-57.

22. Ajzen I. The theory of planned behavior. Organ Behav Hum Decis Process. 1 déc 1991;50(2):179-211.

23. von Wagner C, Steptoe A, Wolf M, Wardle J. Health Literacy and Health Actions: A Review and a Framework From Health Psychology. Health Educ Behav Off Publ Soc Public Health Educ. 1 sept 2008;36:860-77.

24. Wong KC, Woo KZ, Woo KH. Ishikawa Diagram. In: O'Donohue W, Maragakis A, éditeurs. Quality Improvement in Behavioral Health [Internet]. Cham: Springer International Publishing; 2016 [cité 5 oct 2021]. p. 119-32. Disponible sur: https://doi.org/10.1007/978-3-319-26209-3_9

25. Perrin A, Abdalla G, Viprey M, Delahaye F, Mewton N, Ovize M, et al. Prevalence of low health literacy level in two different cardiovascular diseases, myocardical infarct and heart failure. En cours de publication;

26. Chew LD, Bradley KA, Boyko EJ. Brief Questions to Identify Patients With Inadequate Health Literacy. Fam Med. 2004;7.

27. Perrin A, Siqueira do Prado L, Duché A, Schott A-M, Dima AL, Haesebaert J. Using the Brief Health Literacy Screen in Chronic Care in French Hospital Settings: Content Validity of Patient and Healthcare Professional Reports. Int J Environ Res Public Health. janv 2021;18(1):96.

28. Braun V, Clarke V. Using Thematic Analysis in Psychology. Qual Res Psychol. 1 janv 2006;3:77-101.

29. Ishikawa K. Guide to quality control [Internet]. Tokyo: Asian Productivity Organization; 1976 [cité 12 mai 2021]. 254 p. Disponible sur: http://archive.org/details/guidetoqualityco00ishi

30. Powell BJ, Waltz TJ, Chinman MJ, Damschroder LJ, Smith JL, Matthieu MM, et al. A refined compilation of implementation strategies: results from the Expert Recommendations for Implementing Change (ERIC) project. Implement Sci. déc 2015;10(1):1-14.

31. Nutbeam D. Health literacy as a public health goal: a challenge for contemporary health education and communication strategies into the 21st century. Health Promot Int. 1 sept 2000;15(3):259-67.

32. Brega AG, Barnard J, Mabachi NM, Weiss BD, DeWalt DA, Brach C, et al. AHRQ Health Literacy Universal Precautions Toolkit, Second Edition [Internet]. AHRQ Agency for Healthcare Research and Quality; 2015 [cité 21 janv 2021]. Disponible sur: https://www.ahrq.gov/sites/default/files/publications/files/healthlittoolkit2_4.pdf

33. Nache C, Trudeau F. Déterminants psychosociaux des comportements de santé: approches théoriques et opérationnalisation en éducation pour la santé. Spirale - Rev Rech En Éducation. 2000;25(1):89-109.

34. Wittenberg E, Ferrell B, Kanter E, Buller H. Health Literacy: Exploring Nursing Challenges to Providing Support and Understanding. Clin J Oncol Nurs. 1 févr 2018;22(1):53-61. 
35. Cawthon C, Mion LC, Willens DE, Roumie CL, Kripalani S. Implementing Routine Health Literacy Assessment in Hospital and Primary Care Patients. Jt Comm J Qual Patient Saf. 1 févr 2014;40(2):68-AP1.

36. Richard C, Lussier M-T. La littératie en santé, une compétence en mal de traitement. Pédagogie Médicale. 1 mai 2009;10(2):123-30.

37. Ishikawa H, Yano E, Fujimori S, Kinoshita M, Yamanouchi T, Yoshikawa M, et al. Patient health literacy and patient-physician information exchange during a visit. Fam Pract. déc 2009;26(6):517-23.

38. Calkins DR, Davis RB, Reiley P, Phillips RS, Pineo KL, Delbanco TL, et al. Patient-physician communication at hospital discharge and patients' understanding of the postdischarge treatment plan. Arch Intern Med. 12 mai 1997;157(9):1026-30.

39. Ha Dinh TT, Bonner A, Clark R, Ramsbotham J, Hines S. The effectiveness of the teach-back method on adherence and self-management in health education for people with chronic disease: a systematic review. JBI Database Syst Rev Implement Rep. 2016;14(1):210-47.

40. Shivji F, Ramoutar D, Bailey C, Hunter J. Improving communication with primary care to ensure patient safety post-hospital discharge. Br J Hosp Med Lond Engl 2005. 2 janv 2015;76:46-9.

41. Noordman J, Post B, van Dartel A a. M, Slits JMA, Olde Hartman TC. Training residents in patientcentred communication and empathy: evaluation from patients, observers and residents. BMC Med Educ. 2 mai 2019;19(1):128.

42. Bizouarn P. Le médecin, le malade et la confiance. Éthique Santé. 1 sept 2008;5(3):165-72.

43. Di Palo KE, Patel K, Assafin M, Piña IL. Implementation of a Patient Navigator Program to Reduce 30day Heart Failure Readmission Rate. Prog Cardiovasc Dis. 1 sept 2017;60(2):259-66.

44. Kripalani S, Roumie CL, Dalal AK, Cawthon C, Businger A, Eden SK, et al. Effect of a pharmacist intervention on clinically important medication errors after hospital discharge: a randomized trial. Ann Intern Med. 3 juill 2012;157(1):1-10.

45. Luttik ML, Jaarsma T, Moser D, Sanderman R, van Veldhuisen DJ. The importance and impact of social support on outcomes in patients with heart failure: An overview of the literature. J Cardiovasc Nurs. 2005;20(3):162-9.

46. Berger S, Saut AM, Berssaneti FT. Using patient feedback to drive quality improvement in hospitals: a qualitative study. BMJ Open. 1 oct 2020;10(10):e037641.

47. Luther B, Barra J, Martial M-A. Essential Nursing Care Management and Coordination Roles and Responsibilities: A Content Analysis. Prof Case Manag. oct 2019;24(5):249-58.

\section{Figures}




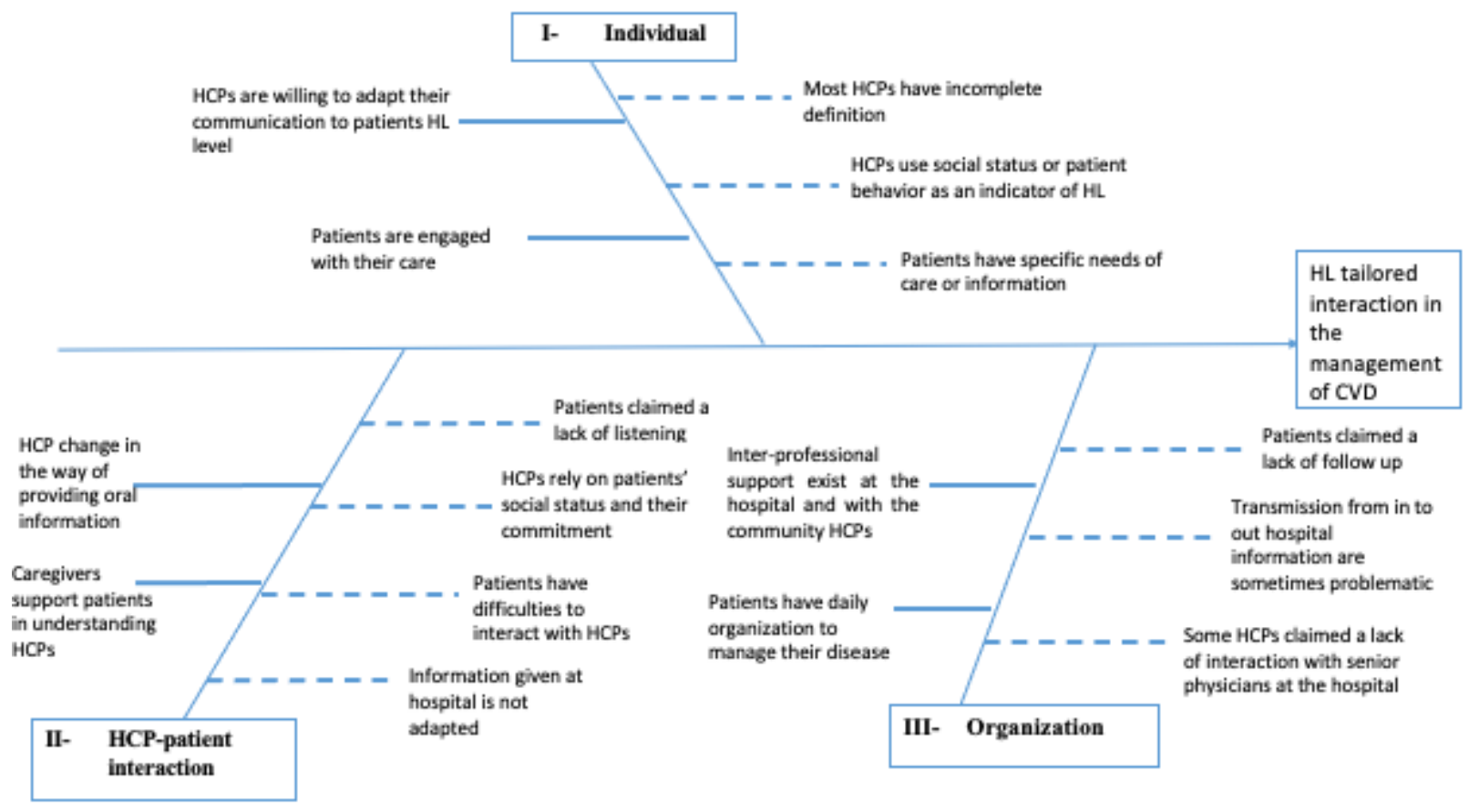

\section{Figure 1}

Fishbone diagram of both patients and HCPs-reported barriers and facilitators. A bold arrow on the left represents facilitators and barriers are on the right represented by dotted lines; illustrating levers to better interaction during the transition from hospital to home. 


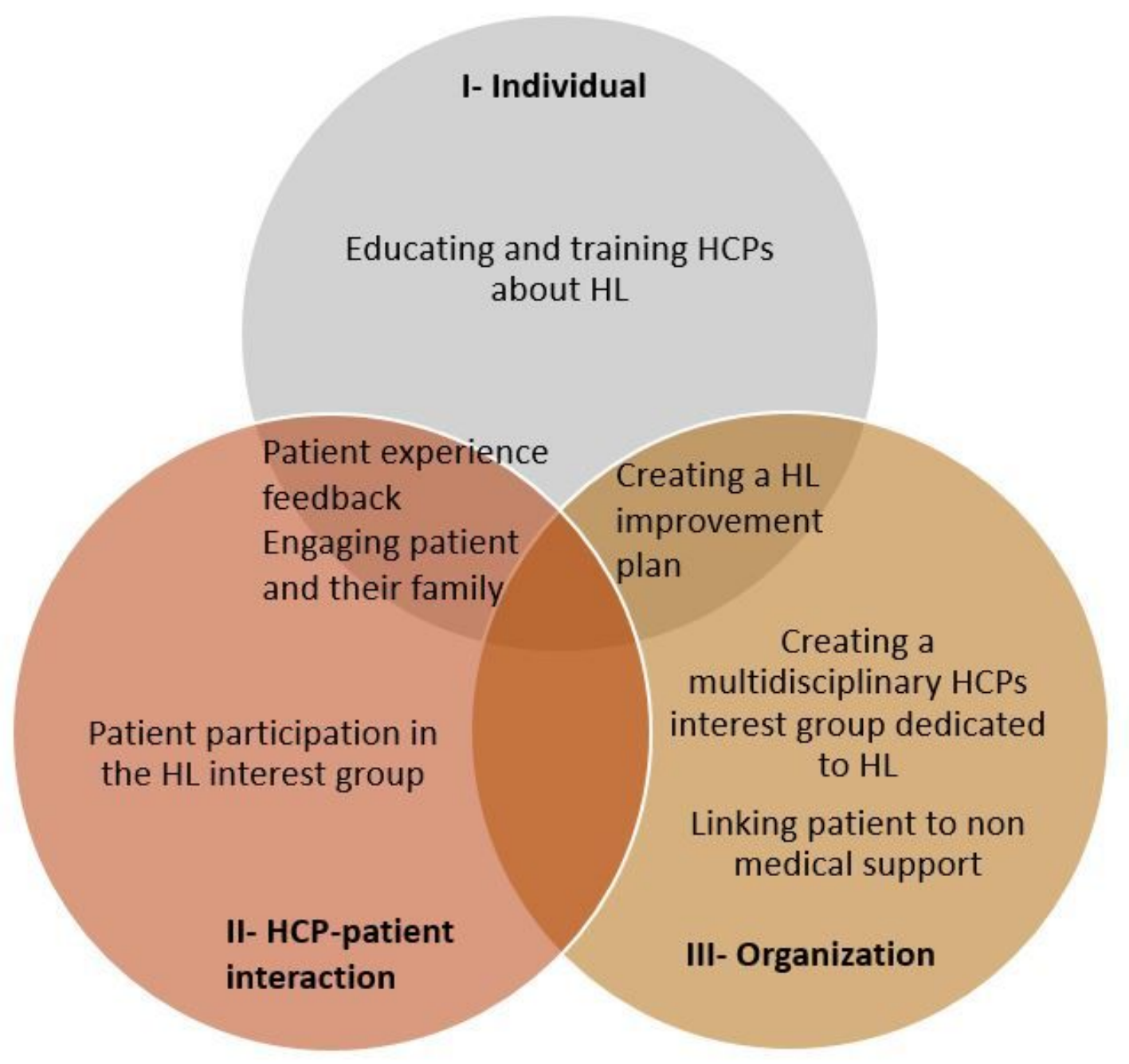

Figure 2

Diagram linking the three groups of Ishikawa barriers and facilitators with the proposed implementation strategies.

\section{Supplementary Files}

This is a list of supplementary files associated with this preprint. Click to download.

- AppendixPerrinetalBMCHSR.docx 